\title{
A New Model for Describing the Rheological Behavior of Heavy and Extra Heavy Crude Oils in the Presence of Nanoparticles
}

\author{
Esteban A. Taborda ${ }^{1, *}$ (D) , Camilo A. Franco ${ }^{1}$, Vladimir Alvarado ${ }^{2}$ (i) and Farid B. Cortés ${ }^{1}$ \\ 1 Grupo de Investigación en Fenómenos de Superficie-Michael Polanyi, Facultad de Minas, \\ Universidad Nacional de Colombia Sede-Medellín, Kra 80 No. 65-223, Medellín, Colombia; \\ caafrancoar@unal.edu.co (C.A.F.); fbcortes@unal.edu.co (F.B.C.) \\ 2 Department of Chemical Engineering, University of Wyoming, Laramie, WY 82071, USA; \\ valvarad@uwyo.edu \\ * Correspondence: eatabord@unal.edu.co; Tel.: +57-4-425-5137
}

Received: 7 November 2017; Accepted: 29 November 2017; Published: 5 December 2017

\begin{abstract}
The present work proposes for the first time a mathematical model for describing the rheological behavior of heavy and extra-heavy crude oils in the presence of nanoparticles. This model results from the combination of two existing mathematical models. The first one applies to the rheology of pseudoplastic substances, i.e., the Herschel-Bulkley model. The second one was previously developed by our research group to model the rheology of suspensions, namely the modified Pal and Rhodes model. The proposed model is applied to heavy and extra heavy crude oils in the presence of nanoparticles, considering the effects of nanoparticles concentration and surface chemical nature, temperature, and crude oil type. All the experimental data evaluated exhibited compelling goodness of fitting, and the physical parameters in the model follow correlate well with variations in viscosity. The new model is dependent of share rate and opens new possibilities for phenomenologically understanding viscosity reduction in heavy crude by adding solid nanoparticles and favoring the scale-up in enhanced oil recovery (EOR) and/or improved oil recovery (IOR) process.
\end{abstract}

Keywords: nanoparticles; heavy oils; modified Pal and Rhodes model; Herschel-Bulkley model; viscosity

\section{Introduction}

Rheology as a science is the study of the deformation of the matter when subjected to stress. This science has been applied commonly in the oil and gas industry for describing the flow behavior of reservoirs fluids (brine and crude oils) as well as of various fluids used in improved oil recovery (IOR) and enhanced oil recovery (EOR) processes such as polymer flooding, surfactant flooding, drilling fluids, fracturing fluids, and cements, among others. Fluids rheology regulates their flow behavior, which is a basic prerequisite for understanding mass transport process in reservoirs and at the surface [1,2]. Consequently, knowing the rheological behavior is of primary importance in the design of field tests for IOR and EOR operations [3], production management, and lifting costs, development of new fluids, reservoir or pipeline pumping. Specifically, in IOR and EOR applications, the viscosity of heavy, and extra-heavy oils may vary drastically depending on the distance from the sand-face, i.e., depending on the shear rate. Therefore, the mathematical modeling of the different physical processes plays a determining role in the understanding of the transport phenomena, particularly in porous media, and hence the possibility of an accurate scale-up of field trials.

Multiple models previously developed served as a starting point to understand rheological behavior of Newtonian or non-Newtonian fluids in the absence of nanoparticles [4-6], including 
Newton's model [7], Ostwald De-Waele model [6], Cross's model [8] , the Carreau model [9], and the Herschel-Bulkley model [10], among others. However, it is worth mentioning that the Herschel-Bulkley model [10] fits well with the rheological data of heavy oil samples, and its parameters allow one to understand the behavior of the system [11].

It is a well-known fact that the addition of solid particles to fluids, other than heavy and extra heavy crudes, leads to increased viscosity [12-16]. This can be explained by Einstein's theory on hydrodynamic viscosity [12], which suggests that an increase in fluid viscosity should occur upon addition of solid particles that is directly proportional to the volume fraction of solids added. However, this widely accepted model does not fit adequately many fluids assessed, and for that reason several researchers have proposed modified mathematical models derived from Einstein's equation $[12,17]$ such as Mooney [15], Eilers [18], Roscoe [19], Chong and Christiansen [20], Maron and Pierce [21], and, Krieger and Dougherty [22]. These models often represent a better approximation to the viscosity response of different types of suspensions than Einstein's equation [23,24]. For applications in crude oils, some authors have studied the addition of asphaltenes in an attempt to understand the viscosity behavior of heavy and extra heavy oil, which has been shown to increase drastically as the asphaltene fraction increases. Other authors have experimentally studied and modeled the rheological behavior of emulsions $\mathrm{W} / \mathrm{O}$ [25-30].

It has previously been shown that the presence of $\mathrm{SiO}_{2}$ nanoparticles has the ability to lower the viscosity of heavy crude [11,31-33]. Said viscosity reduction is produced due to the interaction between the nanoparticles and the heavy hydrocarbons present in the crude oil (asphaltenes and resins). These particles, at a determined concentration according to the characteristics of the crude oil, have the capacity to produce proven structural changes in yield stress and viscosity changes. By means of steady-state rheology measurements of light crudes and de-asphalted oil in the presence of nanoparticles, viscosity increases were obtained $[31,33]$. This result suggests that viscosity reduction is produced precisely by the interaction with asphaltenes.

In subsequent works [31], dynamic rheology measurements are presented using oscillatory tests of heavy crude mixed with nanoparticles; the results confirm the hypothesis that nanoparticles alter the internal structure of crude oil distributing the viscoelastic network formed by asphaltenes and resins in a different way.

Likewise, the first mathematical approximation to understanding the phenomenon was developed through the mathematical modification of the viscosity model in suspensions previously proposed by Pal and Rhodes [33]. They proposed a non-Newtonian shear model based on Einstein's theory, which has been applied to explain the behavior of the viscosity of several crude oils and de-asphalted oils (DAO) varying their content of asphaltenes by their addition. This model has been successfully applied to describe the viscosity response of crude oils (heavy, extra heavy, and de-asphalted oil) to the addition of asphaltenes at different temperatures (293-333 K). The authors consider asphaltenes as semisolid particles, and for this reason one expects the viscosity to increase the higher the asphaltene content [24,34-36]. Similarly, multiple authors have modeled the viscosity of heavy crude as a function of asphaltene content with conventional models derived from Einstein's equation [24,26,29,30,37]. There are models independent of the shear rate, for example, wax-oil gels, which is instead dependent on the strain [38-40]. Our previous model [33] describes well the experimental data previously obtained but is dependent on the shear rate at which the viscosity is measured. For this reason, the proposed new model mainly seeks to explain the nanoparticles-induced viscosity reduction process phenomenologically for the entire shear rate range at which the viscosity is measured.

Likewise, the first mathematical approximation to understanding the phenomenon was developed through the mathematical modification of the viscosity model in suspensions previously proposed by Pal and Rhodes [33]. They proposed a non-Newtonian shear model based on Einstein's theory, which has been applied to explain the behavior of the viscosity of several crude oils and de-asphalted oils (DAO) varying their content of asphaltenes by their addition. This model has been successfully applied to describe the viscosity response of crude oils (heavy, extra heavy, and de-asphalted oil) to 
the addition of asphaltenes at different temperatures (293-333 K). The authors consider asphaltenes as semisolid particles, and for this reason one expects the viscosity to increase the higher the asphaltene content [24,34-36]. Similarly, multiple authors have modeled the viscosity of heavy crude as a function of asphaltene content with conventional models derived from Einstein's equation [24,26,29,30,37]. There are independent models of the shear rate, for example, wax-oil gels, which is instead dependent on the deformation [38-40]. However, our previous model [33] describes well the experimental data previously obtained but is dependent on the shear rate at which the viscosity is measured. For this reason, the proposed new model mainly seeks to explain the nanoparticles-induced viscosity reduction process phenomenologically for the entire shear rate range at which the viscosity is measured.

A complete mathematical approach would allow the application of the model to more complex fluids such as heavy oil and extra heavy oil. Cases of interest involve flow profiles in the presence of nanoparticles to improve the mobility conditions in porous media at reservoir as well as surface conditions. In this work, the model was validated for four types of crude oils, i.e., AK, SU, MB, and $\mathrm{KU}$, including the nanoparticle concentration and temperature effects. In this way, it is possible to guarantee a complete understanding of the phenomena that occur when particles are added to heavy and extra heavy crude oils and provide a great possibility of knowing the flow profiles in commonly encountered heterogeneous porous media, which facilitates technology implementation.

\section{Results and Discussion}

The results section begins with the explanation of the proposed Herschel-Bulkley-Modified Pal and Rhodes (HB-MPR) model. Then, different effects were evaluated for validating the proposed HB-MPR model, including the effects of the nanoparticles surface chemical nature and concentration, temperature, and crude oil type. Finally, the sensitivity analysis for the parameters of the model is presented.

\subsection{Proposed Model}

Einstein's equation for viscosity measurements of suspensions can be expressed as follows:

$$
n_{r}=(1+\beta \phi)
$$

where $n_{r}$ is the relative viscosity, $\beta$ is a constant, commonly 2.5 value is used, and, $\phi$ corresponds to the volume fraction of dispersed particles. This equation presents satisfactory results in the case of highly diluted suspensions and where the interactions between the solids and the fluid are neglected [41]. For this reason, this equation did not accurately model the rheological behavior of heavy crudes with high asphaltene contents.

Recently, Pal and Rhodes [24] proposed a non-Newtonian shear model based on Einstein's theory, which has been applied to explain the behavior of the viscosity of several crude oils and de-asphalted oils (DAO) varying their content of asphaltenes by the addition. The model is as follows:

$$
n_{r}=\left(1-K_{0} \phi\right)^{-2.5}
$$

$K_{0}$ is the solvation constant, which relates to the immobilization of the continuous phase on the dispersed particles surface, so for spherical particles, the form factor is 2.5. As can be seen in Equation (2), the value of viscosity increases when the volume fraction of dispersed particles is large. This study relied on adding asphaltenes to crude oils and de-asphalted oils. Luo and Gu [37] developed a generalized model based on the Pal \& Rhodes' model [23,42]:

$$
n_{r}=\left(1-K_{0} \phi\right)^{-V}
$$

where $V$ refers to the "shape factor" [37,42]. This model has been successfully applied to describe the viscosity response of crude oils (heavy, extra heavy, and de-asphalted oil) to the addition of asphaltenes 
at different temperatures (293-333 K). The authors consider asphaltenes as semisolid particles, and for this reason, one expects the viscosity to increase the higher the asphaltene content [24,34-36]. Similarly, multiple authors have modeled the viscosity of heavy crude as a function of asphaltene content with conventional models derived from Einstein's equation [24,26,29,30,37].

Based on the observed viscosity behavior of the heavy and extra heavy oils, the Pal and Rhodes model was modified [37,42]. Our approach was validated using the experimental rheological results varying the $\mathrm{SiO}_{2}$ nanoparticles concentration [33]. Therefore, it is possible to obtain a mathematical approach that matches what is obtained in the laboratory for a fixed shear rate $(\dot{\gamma})$. The proposed model for a fixed shear rate value is shown in Equation (4):

$$
n_{r}=\left(1+K_{0} \phi\right)^{-V}
$$

In contrast to a colloidal model of asphaltenes, the fraction (f) of nano or colloidal particles leads to a reduction of drag or viscosity by direct reduction of free asphaltene in crude oil, which in principle contributes to a stiffer viscoelastic network in the fluid. The adsorption of asphaltene and its consequent reduced concentration as the result of the availability of surface area on nanoparticles prevents the formation of large drag-causing networks in the bulk of the fluid counter-acting the viscosity-inducing soft asphaltene colloids (aggregates). For completeness, it is necessary to extend this model mainly at reservoir conditions due to the pore size distribution of porous media. Considering that in well stimulation processes, it is very important to determine the viscosity of the fluids that are subjected to varying conditions of agitation and shear rates [43], it is important to count on a mathematical expression that considers several effects such as those associated to the concentration of nanoparticles and shear rates, which allows estimating the viscosity and offer significant help in the design and control of processes. With this in mind, we seek to offer alternatives to the oil and gas industry. In this way, it is possible to extend this model to make it applicable to a whole shear-rate range by combining the conventional models for substances with pseudoplastic behavior like the Herschel-Bulkley model [10], as follows:

$$
\mu=\mu_{0}\left(1+K_{0} \phi\right)^{-V}
$$

The Herschel-Bulkley (H-B) model was used to describe the rheological behavior of heavy and extra heavy oil mixtures in the presence or absence of the nanoparticles as a function of the shear rate $\dot{\gamma}\left(\mathrm{s}^{-1}\right)$ [4-6]. This response in heavy oils is similar to that of polymer solutions in which polymer chains are hydrogen-bound to form larger structures, which can be affected by the strain rate or shear. The flow behavior index $n_{H}$ was investigated for different mixtures and was used as a proxy for the rheological behavior of the fluid. Values of $n_{H}<1.0$ indicate that the fluid follows a pseudoplastic behavior [4]. Consistency index $K_{H}\left(\mathrm{~Pa} \cdot \mathrm{s}^{\mathrm{n}}\right)$ refers to the fluid viscosity. The limiting viscosity parameters $\mu_{0, \gamma}(\mathrm{cP})$ and $\mu_{\infty, \gamma}(\mathrm{CP})$ indicate the behavior of the fluid when subjected to conditions of zero and infinite stresses, respectively. The H-B model is described as follows:

$$
\mu_{0}=K_{H}\left[\dot{\gamma}^{\left(n_{H}-1\right)}\right]+\mu_{\infty, \gamma}
$$

where, $\mu$ is the viscosity of the fluid as a function of shear rate.

Combining these models leads to the Herschel-Bulkley-Modified Pal and Rhodes model (HB-MPR) as shown in Equation (7):

$$
\mu=\left[K_{H}\left(\dot{\gamma}^{\left(n_{H}-1\right)}\right)+\mu_{\infty, \gamma}\right]\left(1+K_{0} \phi\right)^{-V}
$$


The model enables a full understanding impact of nanoparticles in the viscosity of heavy and extra heavy oil when submitted to certain shear. The goodness of fit of the proposed model was evaluated through the correlation coefficient $R^{2}$ and root-mean-square error (RSME\%) [44]:

$$
R S M E \%=100 \sqrt{\frac{1}{k}\left[\sum_{1}^{k}\left(\frac{\mu_{\mathrm{exp}}-\mu_{\text {calc }}}{\mu_{\text {calc }}}\right)^{2}\right]}
$$

where $k$ is the number of observations and $\mu_{\text {exp }}$ and $\mu_{\text {calc }}$ are the observed and calculated values of viscosity, respectively. Also, to evaluate the robustness of the proposed model, existing data of rheology of heavy and extra heavy crude oils in the presence of nanoparticles was taken from specialized literature [31-33]. Hence, from previous works crude oil samples SU and AK were analyzed, corresponding to a heavy and an extra heavy oil, respectively.

\subsection{Nanoparticle Concentration Effect}

Figure 1a-c shows the experimental rheological measurement of (a) MB and (b) KU crude oils in the presence of $\mathrm{SiO}_{2}$ nanoparticles at concentrations of 0,500 , and $1000 \mathrm{mg} / \mathrm{L}$, and a temperature of $298 \mathrm{~K}$. Also, Figure 1c shows the literature data for SU heavy oil together with the proposed model fitting. Results show that by increasing the concentration of nanoparticles in the medium, the viscosity of the sample decreases. Also, it is observed from Figure 1 that the HB-MPR fits the experimental data reasonably well.

Table 1 shows the parameters of the HB-MPR model for each crude oil evaluated at different concentrations of $\mathrm{SiO}_{2}$ nanoparticles and different temperatures corresponding to both experimental datasets. Statistical parameters of the goodness of fitting are also presented to evaluate the reliability of the model. According to the $R S M E \%$ values $<10$, it can be concluded that the HB-MPR model describes the experimental data of rheology excellently.
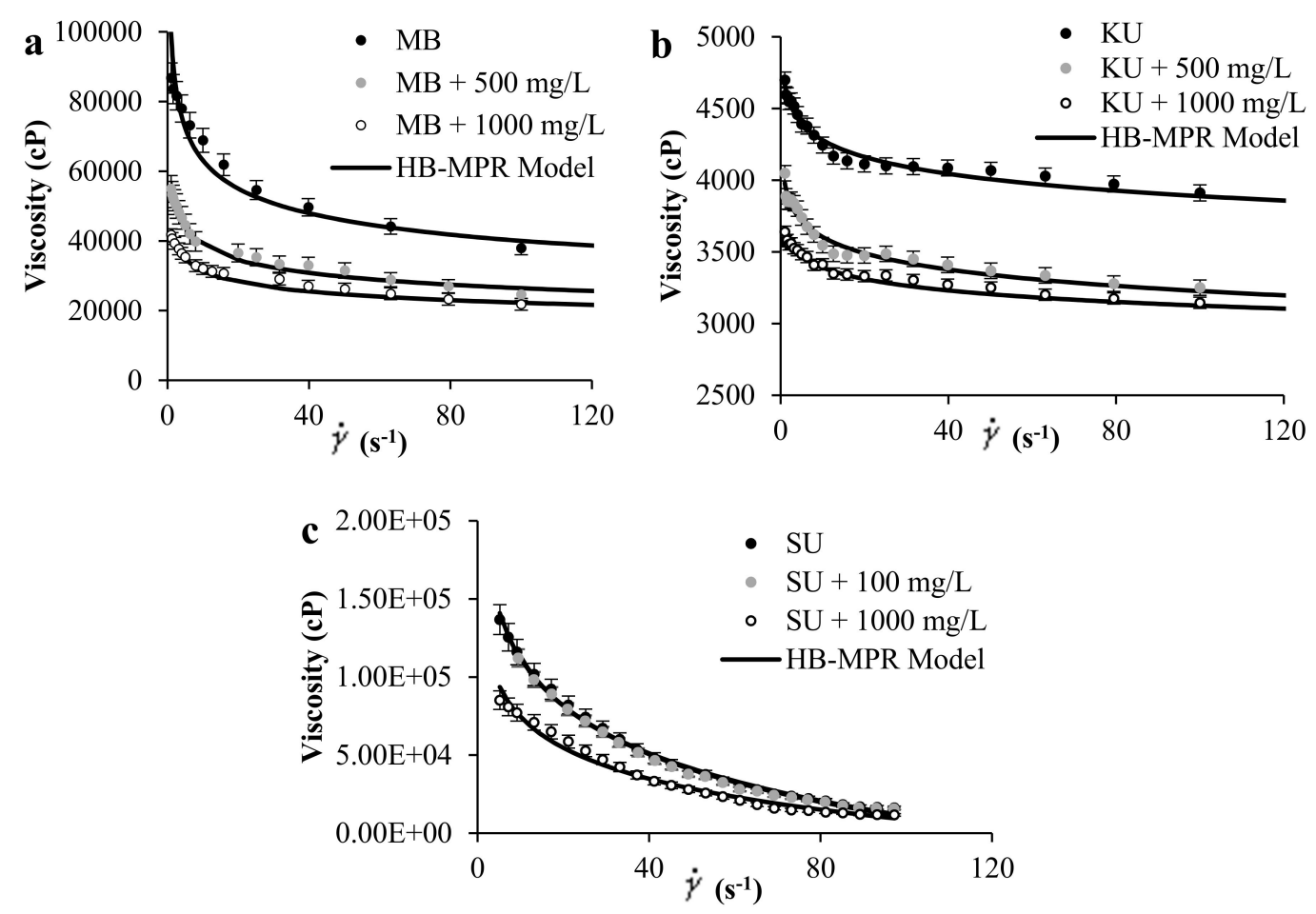

Figure 1. Viscosity of (a) MB heavy oil, (b) KU heavy oil, and (c) SU heavy oil, in the presence of SiO2 nanoparticles at different concentrations at $298 \mathrm{~K}$ and shear rate between 0 and $120 \mathrm{~s}^{-1}$. 
Table 1. HB-MPR Model parameters for experimental data and literature data [31-33].

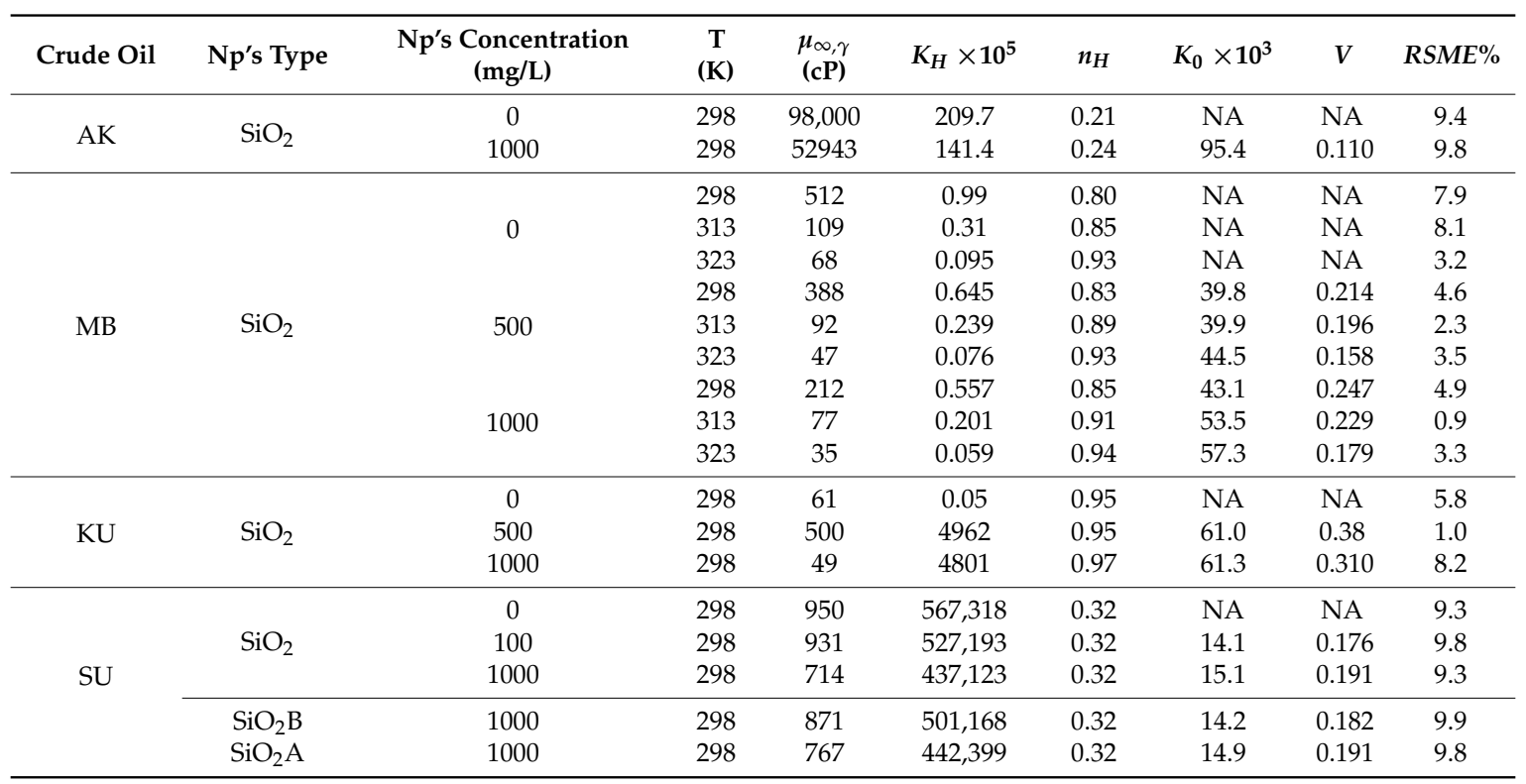

\subsection{Temperature Effect}

Figure 2 shows the experimental rheological measurement of $\mathrm{MB}$ crude oil in the presence of $\mathrm{SiO}_{2}$ nanoparticles at concentrations of $1000 \mathrm{mg} / \mathrm{L}$, and at temperature values of 298,313 , and $323 \mathrm{~K}$. It is observed from Figure 2 that the proposed model fits the experimental data well and that by increasing the temperature of the system, the viscosity tends to decrease. The parameters of the HB-MPR model obtained for different temperatures are presented in Table 1.

For the crude oil evaluated, a considerable decrease in viscosity occurs by modifying the operating temperature. In this way, the parameters $\mu_{\infty, \gamma}, K_{H}, n_{H}$, and $K_{0}$ follow a trend similar to that presented in effect of the concentration of nanoparticles. For example, $\mu_{\infty, \gamma}$ follows a consistent trend according to the increase in temperature. As temperature increases, this value decreases and is consistent due to the decrease in viscosity.

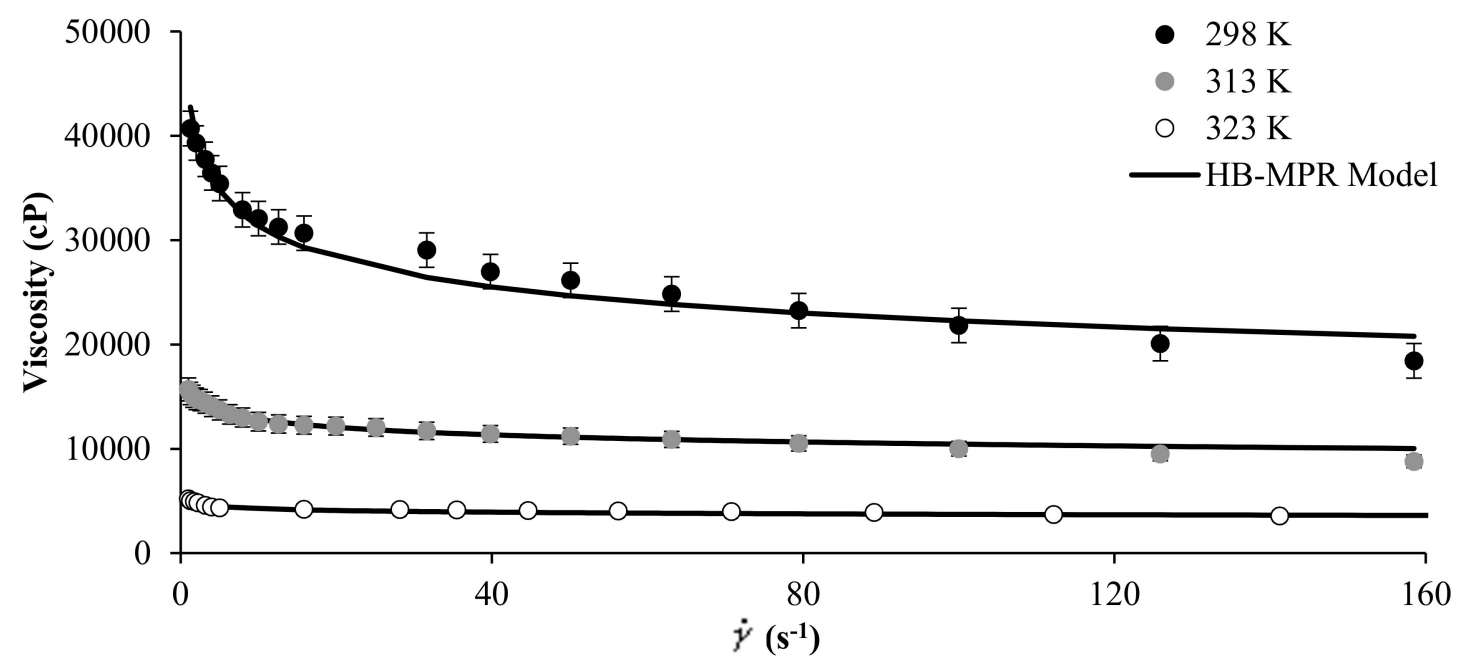

Figure 2. Viscosity of $\mathrm{MB}$ heavy oil in the presence of $1000 \mathrm{mg} / \mathrm{L}$ of $\mathrm{SiO}_{2}$ nanoparticles at different temperatures and shear rate between 0 and $160 \mathrm{~s}^{-1}$.

$K_{H}$ has the same behavior. The parameter $n_{H}$ increases as the temperature increases, showing a close behavior to Newtonian fluids. The parameter $K_{0}$ also increases as the temperature of the system 
increases, favoring the solvation. Parameter $V$ shows a clear tendency to decrease with the increase in the temperature and is possibly due to a change in the geometric form decreasing the size of the particle after contacting the asphaltene in the crude oil.

\subsection{Effect of Chemical Nature of the Crude Oil}

Figure 3 shows the experimental rheological measurement of $\mathrm{MB}, \mathrm{SU}, \mathrm{KU}$, heavy oils, and AK extra heavy oil in the presence of $\mathrm{SiO}_{2}$ nanoparticles at concentrations of $1000 \mathrm{mg} / \mathrm{L}$, and for a fixed temperature of $298 \mathrm{~K}$. The HB-MPR fits perfectly with the experimental data obtained. The parameters of the HB-MPR model are presented in Table 1. The parameter related to the flow index for the extra heavy oil has a value very far from the unit, and it can be explained by the high content of asphaltenes, creating a viscoelastic network with strong pseudoplastic tendency very far from a Newtonian behavior [45]. The difference between the values of different crude oils can be explained by the nature of the crude oil, the value of the $\mu_{\infty, \gamma}$ parameter is much higher for an extra heavy crude (AK) than for a heavy oil (MB, SU, or KU).

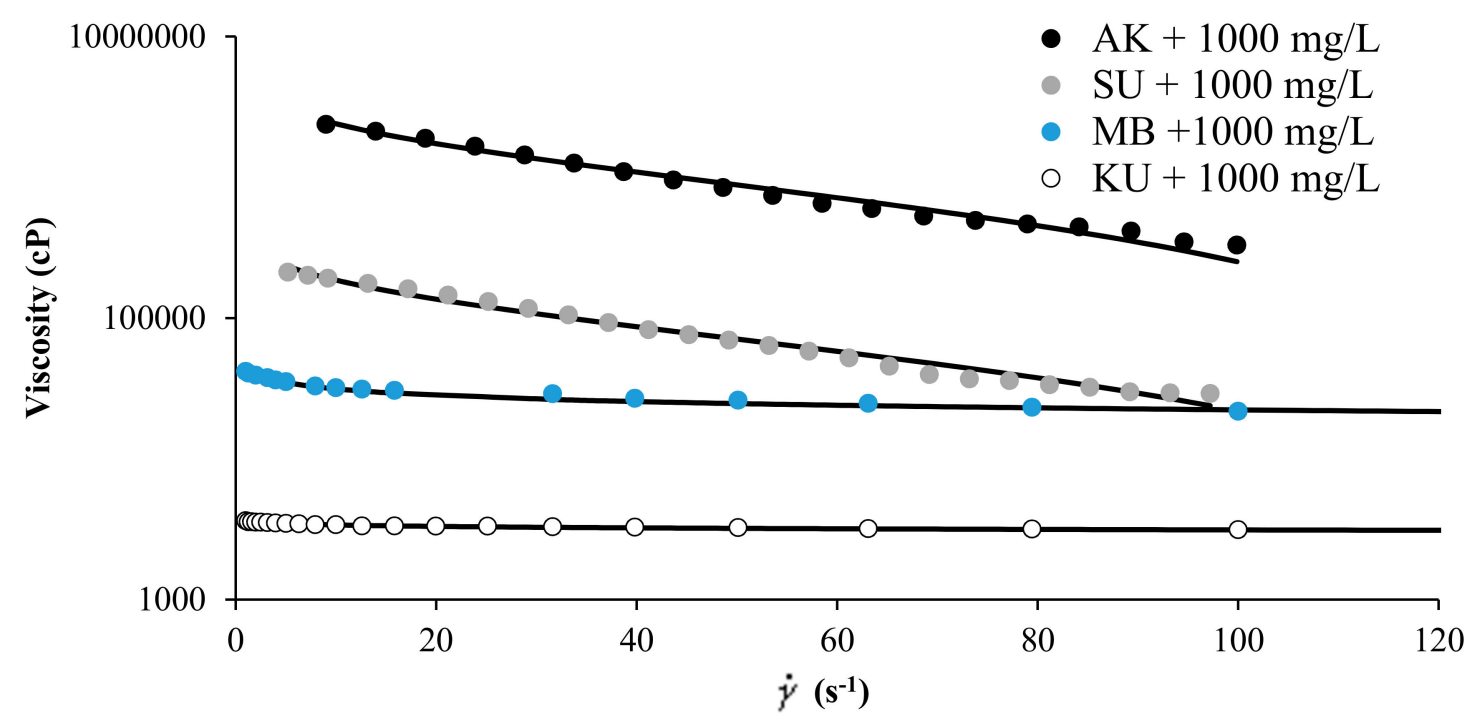

Figure 3. Viscosity of $\mathrm{MB}, \mathrm{SU}$, and $\mathrm{KU}$ heavy oils, and $\mathrm{AK}$ extra heavy oil in the presence of $\mathrm{SiO}_{2}$ nanoparticles at $1000 \mathrm{mg} / \mathrm{L}$ and $298 \mathrm{~K}$ and shear rate between 0 and $120 \mathrm{~s}^{-1}$.

\subsection{Effect of the Surface Chemistry of Nanoparticles}

Figure 4 shows the literature rheological data measurement of SU heavy crude oil [33] in the presence of $\mathrm{SiO}_{2}$ nanoparticles with acid, neutral and basic surface at concentrations of $1000 \mathrm{mg} / \mathrm{L}$ and $298 \mathrm{~K}$, together with the proposed model fitting. Also, the corresponding parameters of the HB-MPR model are presented in Table 1. It can be seen how the HB-MPR model fits the experimental data reported. The model can be extended and applied not only to various types of crude oil but different kinds of nanoparticles. A clear trend of the parameters is observed according to the change in the viscosity of the mixtures. 


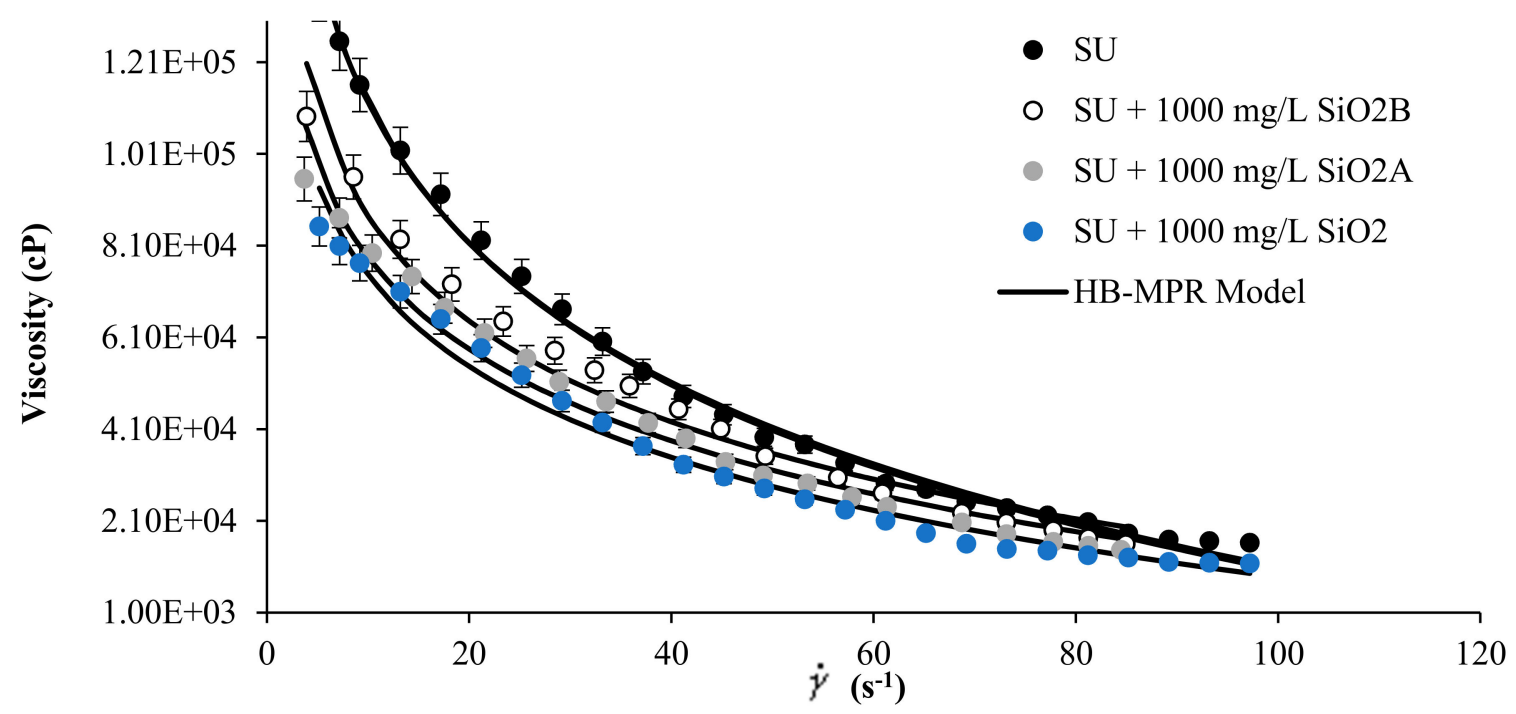

Figure 4. Viscosity of $\mathrm{SU}$ heavy oil in the presence of $\mathrm{SiO}_{2}$ nanoparticles neutral $\left(\mathrm{SiO}_{2}\right), \mathrm{acid}\left(\mathrm{SiO}_{2} \mathrm{~A}\right)$, and basic $\left(\mathrm{SiO}_{2} \mathrm{~B}\right)$ at $1000 \mathrm{mg} / \mathrm{L}$ and $298 \mathrm{~K}$ and shear rate between 0 and $120 \mathrm{~s}^{-1}$.

The parameter $\mu_{\infty, \gamma}$ refers to a value of viscosity measured at an infinite shear rate, and as can be seen in Table 1, this value changes according to how the viscosity of each sample changes. A logical trend is observed according to the increase in the concentration of nanoparticles. As particle concentration increases, this value decreases and is consistent due to the decrease in viscosity.

The behavior of the parameter $K_{H}$ follows trends similar to the one exhibited by parameter $\mu_{\infty, \gamma}$, i.e., its numerical value decreases as the concentration of nanoparticles increases. This parameter refers to the index of consistency of the fluid, and for this reason, it can be interpreted as a decrease in the consistency and the internal resistance of the fluid to flow [10]. Hence, when its viscosity decreases, the numerical value of its consistency also decreases.

The parameter $n_{H}$ is known as the flow index of the fluid, when its value is 1 , the fluid can be considered Newtonian, when it is less than 1, it is considered non-Newtonian type pseudoplastic, and the further away from 1 , it is less Newtonian. Note that this value is always less than 1 in all fluids evaluated. However, it can be seen how this value approaches the unit as the nanoparticle content increases. The results of this parameter are consistent with expected, as viscosity decreases, this class of fluids tend to become Newtonian behavioral fluids [10].

The parameter $K_{0}$, also known as the solvation constant, can be related to the immobilization of the continuous phase on the dispersed particles surface. As the nanoparticle concentration increases, the increase in the numerical value of this parameter can be explained by the increase in the immobilization of the continuous phase in the vicinity of the surface of the nanoparticles. This immobilization is greater because there are more solid particles, thus, a larger contact surface.

Parameter $V$ relates to the shape of the dispersed particles. By increasing the concentration of particles, there may be aggregation phenomena between them or interacting with the asphaltenes by changing the geometric shape of the particles. For this reason, as the concentration of nanoparticles increases, the numerical value of this parameter increases, suggesting a possible growth in the geometric shape of nanoparticles after contact with asphaltene. The interesting thing about the evaluation of the parameter is that there is again a clear tendency to increase with the increase of nanoparticles of the system.

\subsection{Sensitivity Analysis for Parameters.}

A sensitivity analysis to the mathematical model is presented in this section. The objective of the sensitivity analysis is to determine the effects of each parameter on the behavior of the response 
variable, in this case, the viscosity of the suspension of heavy crude with nanoparticles. Figure 5 shows the sensitivity analysis modifying up to $20 \%$ the value of each parameter.

The analysis was performed for crude $\mathrm{SU}$ in the presence of nanoparticles with a concentration of $1000 \mathrm{mg} / \mathrm{L}$ of $\mathrm{SiO}_{2}$ at $298 \mathrm{~K}$. According to the sensitivity analysis performed, it is possible to determine which parameter has more effect on the viscosity according to the proposed model. The color lines represent the change in 10 and $20 \%$ positively and negatively of each of the parameters.

From Figure 5, the sensitivity of each parameter participating in the proposed model can be observed. Clearly, the model is less sensitive to changes in the parameter that is related to the viscosity measured at an infinite shear rate. The other parameters belonging to the model have more incidence on the viscosity calculated from the model. It can be considered that the parameters $K_{H}, K_{0}, n_{H}$, and $V$ have a similar impact on the behavior of the model.

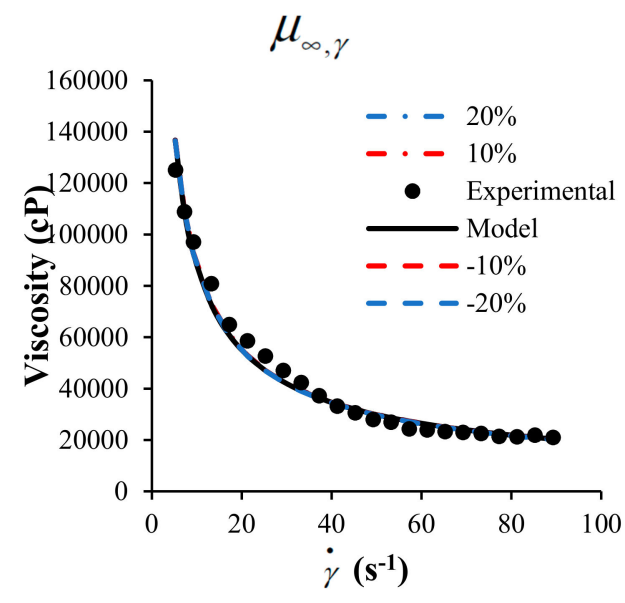

(a)

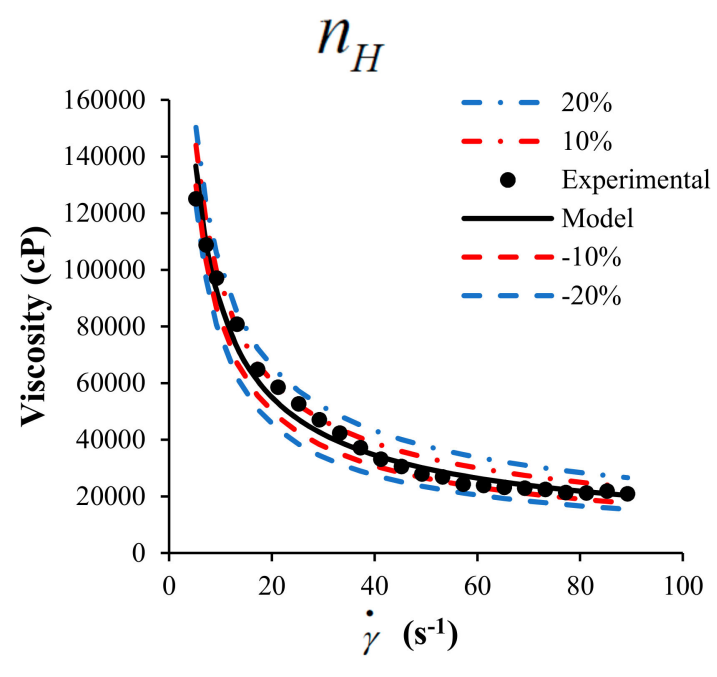

(c)

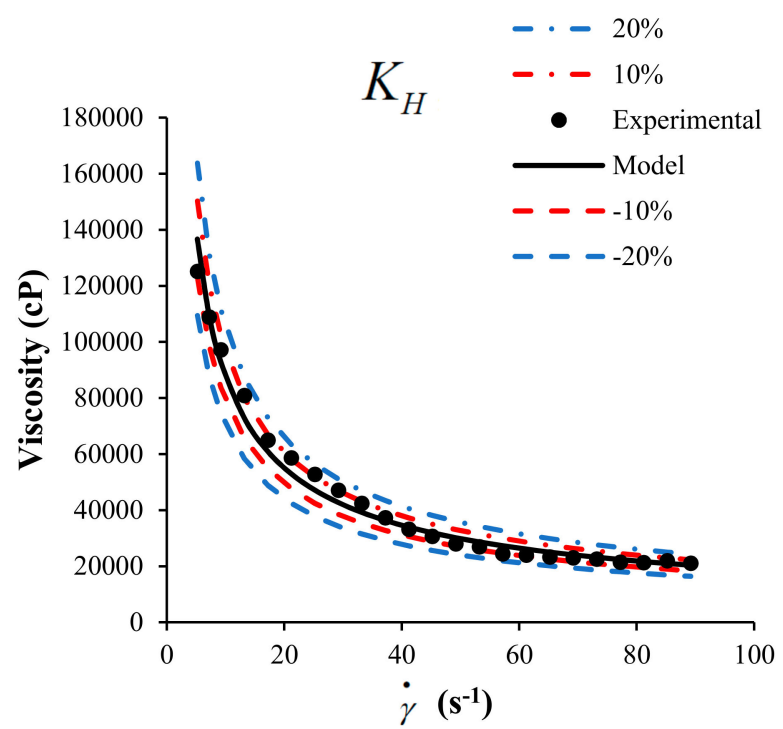

(b)

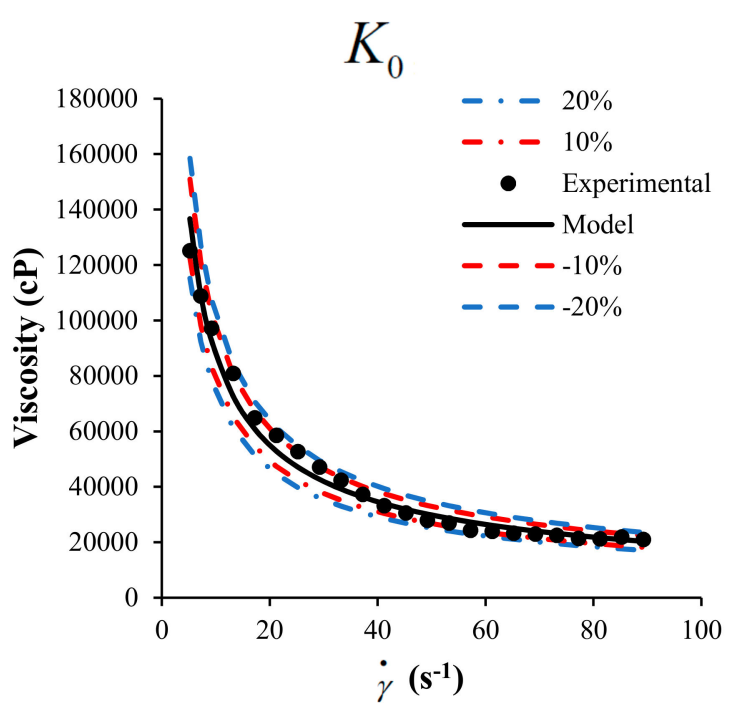

(d)

Figure 5. Cont. 


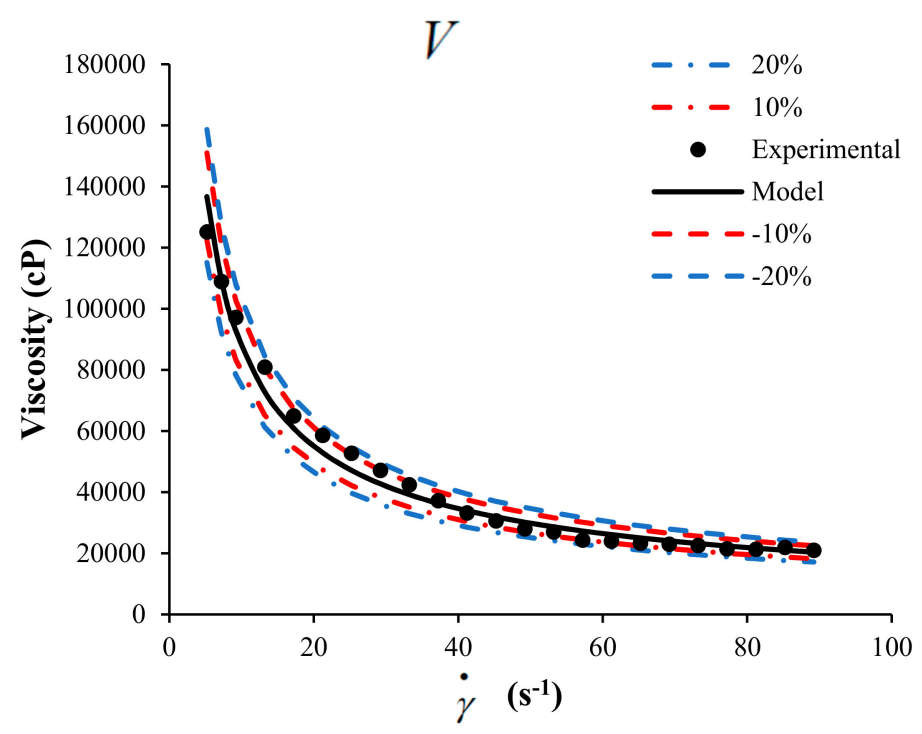

(e)

Figure 5. Sensitivity analysis for the HB-MPR parameters (a) $\mu_{\infty, \gamma},(\mathbf{b}) K_{H}$, (c) $n_{H}$, (d) $K_{0}$, and (e) $V$.

\section{Materials and Methods}

\subsection{Materials and Chemical}

Two heavy crude oils were used as heavy oils matrices. The properties of the selected oils are presented in Table 2. Commercial nanoparticles of silica gel $\left(\mathrm{SiO}_{2}\right)$ were used in this study, as provided by the supplier. The $\mathrm{SiO}_{2}$ nanoparticles of $8 \mathrm{~nm}$ and $389 \mathrm{mg} / \mathrm{m}^{2}$ [32] were obtained from Sigma-Aldrich (St. Louis, MO, USA).

Table 2. Crude oil properties at $298 \mathrm{~K}$.

\begin{tabular}{|c|c|c|c|c|}
\hline Crude Oil & Type & Density (gr/cc) & Viscosity (cP) & $\mathrm{C}_{5}$-asphaltene (wt \%) \\
\hline MB & Heavy oil & 0.98 & $1.0 \times 10^{5}$ & 23.7 \\
\hline KU & Heavy oil & 0.96 & $4.7 \times 10^{3}$ & 18.2 \\
\hline
\end{tabular}

\subsection{Evaluation of Nanoparticles as Viscosity Reducers}

An ARES rotational rheometer (TA Instruments, New Castle, PA, USA) was used to perform the rheological characterization of the crude oil in the presence and absence of nanoparticles. The equipment has a Peltier cell to control the temperature of the system. The values selected to perform the measurements were 298, 313, and $323 \mathrm{~K}$, with shear rates between 1-150 s $\mathrm{s}^{-1}$. The selected geometry is of $50 \mathrm{~mm}$ parallel plates at a gap of $300 \mu \mathrm{m}$. The mixtures of crude and nanoparticles were carried out in a mixer model HP130915Q from Thermo Scientific (Waltham, MA, USA), at $500 \mathrm{rpm}$ for $30 \mathrm{~min}$ at room temperature. Each measurement was made in triplicate to obtain statistically acceptable results.

The $\mathrm{SiO}_{2}$ sample was selected to evaluate the effect of concentration on the rheological properties of the heavy oil matrix. In previous works [46-49], it was demonstrated that $\mathrm{SiO}_{2}$ nanoparticles had a great affinity for the asphaltenes and heavy compounds in oil, reducing the asphaltenes aggregates size present in the heavy oil matrix. For this reason, the addition of these particles should positively affect oil rheological properties, mainly by reducing the oil viscosity. The concentrations tested were 500 and $1000 \mathrm{mg} / \mathrm{L}$. 


\section{Conclusions}

In this communication, the first mathematical approach to calculating the viscosity as a function of the concentration of nanoparticles is presented and expressed as a function of volume fraction and share rate based on a combination of the modified Pal and Rhodes model for suspensions viscosity and the steady-state rheological model of Herschel-Buckley. The model fits the experimental data well for volume fractions between 0 and $3.7 \times 10^{-6}$. The model was validated using experimental data obtained by rheological measurements of steady state at various concentrations of nanoparticles and different temperatures and also using data from the literature of works previously published by our research group. All parameters evaluated are explained and follow an established trend as the nanoparticle concentration and temperature change. The numerical values of all parameters are consistent according to the decrease in viscosity obtained by increasing both the temperature and the concentration of nanoparticles. Using a sensitivity analysis, it was determined that the model is very sensitive to the parameters $n_{H}$ and $K_{H}$. These parameters present the highest effect on the viscosity.

The results of this research serve to increase the understanding of the reduction of viscosity phenomenologically and open a new panorama to modeling the phenomena that involve the use of nanotechnology in the oil and gas industry.

Acknowledgments: The authors acknowledge COLCIENCIAS, ANH and Universidad Nacional de Colombia for their support, which was provided by Agreement 647 of 2015. Also the authors would like to acknowledge to the University of Wyoming for their logistical support.

Author Contributions: E.A.T. performed the experiments, analyzed the data and wrote the paper. V.A. contributed with the design of the experiments, analysys of the data, and provide the materials. C.A.F. contributed with the evaluation of the model, and analysis of the data, and F.B.C. contributed with the development of the model and the writing of the paper.

Conflicts of Interest: The authors declare no conflicts of interest.

\section{References}

1. Aliyu, M.D.; Chen, H.-P. Sensitivity analysis of deep geothermal reservoir: Effect of reservoir parameters on production temperature. Energy 2017, 129, 101-113. [CrossRef]

2. Hosseinifar, P.; Jamshidi, S. A new correlative model for viscosity estimation of pure components, bitumens, size-asymmetric mixtures and reservoir fluids. J. Pet. Sci. Eng. 2016, 147, 624-635. [CrossRef]

3. Zhang, J.; Chen, X.-P.; Zhang, D.; Xu, J.-Y. Rheological behavior and viscosity reduction of heavy crude oil and its blends from the Sui-zhong oilfield in China. J. Pet. Sci. Eng. 2017, 156, 563-574. [CrossRef]

4. Nik, W.W.; Ani, F.; Masjuki, H.; Giap, S.E. Rheology of bio-edible oils according to several rheological models and its potential as hydraulic fluid. Ind. Crops Prod. 2005, 22, 249-255. [CrossRef]

5. Sarpkaya, T. Flow of non-Newtonian fluids in a magnetic field. AIChE J. 1961, 7, 324-328. [CrossRef]

6. Shao, S.; Lo, E.Y. Incompressible SPH method for simulating Newtonian and non-Newtonian flows with a free surface. Adv. Water Resour. 2003, 26, 787-800. [CrossRef]

7. Shames, I.H.; Shames, I.H. Mechanics of Fluids; McGraw-Hill: New York, NY, USA, 1982.

8. Cross, M.M. Rheology of non-Newtonian fluids: A new flow equation for pseudoplastic systems. J. Colloid Sci. 1965, 20, 417-437. [CrossRef]

9. Carreau, P.J. Rheological equations from molecular network theories. Trans. Soc. Rheol. 1972, 16, 99-127. [CrossRef]

10. Herschel, W.H. The change in viscosity of oils with the temperature. Ind. Eng. Chem. 1922, 14, 715-722. [CrossRef]

11. Taborda, E.A.; Alvarado, V.; Cortés, F.B. Effect of $\mathrm{SiO}_{2}$-based nanofluids in the reduction of naphtha consumption for heavy and extra-heavy oils transport: Economic impacts on the Colombian market. Energy Convers. Manag. 2017, 148, 30-42. [CrossRef]

12. Einstein, A. Eine neue bestimmung der moleküldimensionen. Annalen der Physik 1906, 324, 289-306. [CrossRef]

13. Guth, E.; Simha, R. Untersuchungen über die viskosität von suspensionen und lösungen. 3. über die viskosität von kugelsuspensionen. Colloid Polym. Sci. 1936, 74, 266-275. [CrossRef] 
14. Kitano, T.; Kataoka, T.; Shirota, T. An empirical equation of the relative viscosity of polymer melts filled with various inorganic fillers. Rheol. Acta 1981, 20, 207-209. [CrossRef]

15. Mooney, M. The viscosity of a concentrated suspension of spherical particles. J. Colloid Sci. 1951, 6, 162-170. [CrossRef]

16. Thomas, D.G. Transport characteristics of suspension: VIII. A note on the viscosity of Newtonian suspensions of uniform spherical particles. J. Colloid Sci. 1965, 20, 267-277. [CrossRef]

17. Ouerfelli, N.; Bouanz, M. A shear viscosity study of cerium (III) nitrate in concentrated aqueous solutions at different temperatures. J. Phys. Condens. Matter 1996, 8, 2763. [CrossRef]

18. Eilers, V.H. Die viskosität von emulsionen hochviskoser stoffe als funktion der konzentration. Kolloid-Zeitschrift 1941, 97, 313-321. [CrossRef]

19. Roscoe, R. The viscosity of suspensions of rigid spheres. Br. J. Appl. Phys. 1952, 3, 267. [CrossRef]

20. Chong, J.; Christiansen, E.; Baer, A. Rheology of concentrated suspensions. J. Appl. Polym. Sci. 1971, 15, 2007-2021. [CrossRef]

21. Maron, S.H.; Pierce, P.E. Application of Ree-Eyring generalized flow theory to suspensions of spherical particles. J. Colloid Sci. 1956, 11, 80-95. [CrossRef]

22. Krieger, I.M.; Dougherty, T.J. A mechanism for non-Newtonian flow in suspensions of rigid spheres. J. Rheol. 1959, 3, 137-152. [CrossRef]

23. Pal, R.; Rhodes, E. A novel viscosity correlation for non-Newtonian concentrated emulsions. J. Colloid Interface Sci. 1985, 107, 301-307. [CrossRef]

24. Pal, R.; Vargas, F. On the interpretation of viscosity data of suspensions of asphaltene nano-aggregates. Can. J. Chem. Eng. 2014, 92, 573-577. [CrossRef]

25. Barré, L.; Simon, S.; Palermo, T. Solution properties of asphaltenes. Langmuir 2008, 24, 3709-3717. [CrossRef] [PubMed]

26. Bouhadda, Y.; Bendedouch, D.; Sheu, E.; Krallafa, A. Some preliminary results on a physico-chemical characterization of a Hassi Messaoud petroleum asphaltene. Energy Fuels 2000, 14, 845-853. [CrossRef]

27. Jezequel, P.; Flaud, P.; Quemada, D. Rheological properties and flow of concentrated disperse media. II-Steady and unsteady flow analysis of heavy crude oil emulsions. Chem. Eng. Commun. 1985, 32, 85-99. [CrossRef]

28. Plegue, T.; Frank, S.; Fruman, D.; Zakin, J. Concentrated viscous crude oil-in-water emulsions for pipeline transport. Chem. Eng. Commun. 1989, 82, 111-122. [CrossRef]

29. Sheu, E.Y.; Storm, D.A.; Maureen, M. Asphaltenes in polar solvents. J. Non-Cryst. Solids 1991, 131, $341-347$. [CrossRef]

30. Van der Waarden, M. Viscosity and electroviscous effect of emulsions. J. Colloid Sci. 1954, 9, $215-222$. [CrossRef]

31. Taborda, E.A.; Alvarado, V.; Franco, C.A.; Cortés, F.B. Rheological demonstration of alteration in the heavy crude oil fluid structure upon addition of nanoparticles. Fuel 2017, 189, 322-333. [CrossRef]

32. Taborda, E.A.; Franco, C.A.; Lopera, S.H.; Alvarado, V.; Cortés, F.B. Effect of nanoparticles/nanofluids on the rheology of heavy crude oil and its mobility on porous media at reservoir conditions. Fuel 2016, 184, 222-232. [CrossRef]

33. Taborda, E.A.; Franco, C.A.; Ruiz, M.A.; Alvarado, V.; Cortés, F.B. Experimental and Theoretical Study of Viscosity Reduction in Heavy Crude Oils by Addition of Nanoparticles. Energy Fuels 2017, 31, 1329-1338. [CrossRef]

34. Acevedo, S.; Castro, A.; Negrin, J.G.; Fernández, A.; Escobar, G.; Piscitelli, V.; Delolme, F.; Dessalces, G. Relations between asphaltene structures and their physical and chemical properties: The rosary-type structure. Energy Fuels 2007, 21, 2165-2175. [CrossRef]

35. Mullins, O.C.; Betancourt, S.S.; Cribbs, M.E.; Dubost, F.X.; Creek, J.L.; Andrews, A.B.; Venkataramanan, L. The colloidal structure of crude oil and the structure of oil reservoirs. Energy Fuels 2007, 21, 2785-2794. [CrossRef]

36. Pierre, C.; Barré, L.; Pina, A.; Moan, M. Composition and heavy oil rheology. Oil Gas Sci. Technol. 2004, 59, 489-501. [CrossRef]

37. Luo, P.; Gu, Y. Effects of asphaltene content on the heavy oil viscosity at different temperatures. Fuel 2007, 86, 1069-1078. [CrossRef] 
38. Frigaard, I.A.; Paso, K.G.; de Souza Mendes, P.R. Bingham's model in the oil and gas industry. Rheol. Acta 2017, 56, 259-282. [CrossRef]

39. Paso, K.; Kompalla, T.; Oschmann, H.J.; Sjöblom, J. Rheological degradation of model wax-oil gels. J. Dispers. Sci. Technol. 2009, 30, 472-480. [CrossRef]

40. Paso, K.; Silset, A.; Sørland, G.; Gonçalves, M.D.A.; Sjöblom, J. Characterization of the formation, flowability, and resolution of Brazilian crude oil emulsions. Energy Fuels 2008, 23, 471-480. [CrossRef]

41. Soleymanzadeh, A.; Gahrooei, H.R.E.; Joekar-Niasar, V. A New Empirical Model for Foam Rheology. J. Energy Resour. Technol. 2017. [CrossRef]

42. Pal, R.; Rhodes, E. Viscosity/concentration relationships for emulsions. J. Rheol. 1989, 33, 1021-1045. [CrossRef]

43. Economides, M.J.; Nolte, K.G. Reservoir Stimulation; John Wiley \& Sons: New York, NY, USA, 2000.

44. Montgomery, D.C. Design and Analysis of Experiments; John Wiley \& Sons: Hoboken, NJ, USA, 2008.

45. Ilyin, S.; Arinina, M.; Polyakova, M.; Bondarenko, G.; Konstantinov, I.; Kulichikhin, V.; Malkin, A. Asphaltenes in heavy crude oil: Designation, precipitation, solutions, and effects on viscosity. J. Pet. Sci. Eng. 2016, 147, 211-217. [CrossRef]

46. Franco, C.; Patiño, E.; Benjumea, P.; Ruiz, M.A.; Cortés, F.B. Kinetic and thermodynamic equilibrium of asphaltenes sorption onto nanoparticles of nickel oxide supported on nanoparticulated alumina. Fuel 2013, 105, 408-414. [CrossRef]

47. Franco, C.A.; Montoya, T.; Nassar, N.N.; Pereira-Almao, P.; Cortés, F.B. Adsorption and subsequent oxidation of colombian asphaltenes onto Nickel and/or Palladium oxide supported on fumed silica nanoparticles. Energy Fuels 2013, 27, 7336-7347. [CrossRef]

48. Franco, C.A.; Nassar, N.N.; Ruiz, M.A.; Pereira-Almao, P.; Cortés, F.B. Nanoparticles for inhibition of asphaltenes damage: Adsorption study and displacement test on porous media. Energy Fuels 2013, 27, 2899-2907. [CrossRef]

49. Nassar, N.N.; Betancur, S.; Acevedo, S.; Franco, C.A.; Cortés, F.B. Development of a Population Balance Model to Describe the Influence of Shear and Nanoparticles on the Aggregation and Fragmentation of Asphaltene Aggregates. Ind. Eng. Chem. Res. 2015, 54, 8201-8211. [CrossRef]

(C) 2017 by the authors. Licensee MDPI, Basel, Switzerland. This article is an open access article distributed under the terms and conditions of the Creative Commons Attribution (CC BY) license (http:/ / creativecommons.org/licenses/by/4.0/). 